\title{
Epistemology Shmepistemology: Moral Error Theory and Epistemic Expressivism
}

DOI:

10.1080/0020174X.2017.1291362

\section{Document Version}

Accepted author manuscript

Link to publication record in Manchester Research Explorer

\section{Citation for published version (APA):}

Ingram, S. (2018). Epistemology Shmepistemology: Moral Error Theory and Epistemic Expressivism. Inquiry, 61(7), 649. https://doi.org/10.1080/0020174X.2017.1291362

\section{Published in:}

Inquiry

\section{Citing this paper}

Please note that where the full-text provided on Manchester Research Explorer is the Author Accepted Manuscript or Proof version this may differ from the final Published version. If citing, it is advised that you check and use the publisher's definitive version.

\section{General rights}

Copyright and moral rights for the publications made accessible in the Research Explorer are retained by the authors and/or other copyright owners and it is a condition of accessing publications that users recognise and abide by the legal requirements associated with these rights.

\section{Takedown policy}

If you believe that this document breaches copyright please refer to the University of Manchester's Takedown Procedures [http://man.ac.uk/04Y6Bo] or contact uml.scholarlycommunications@manchester.ac.uk providing relevant details, so we can investigate your claim.

\section{OPEN ACCESS}




\title{
Epistemology Shmepistemology: Moral Error Theory and Epistemic Expressivism
}

\author{
Stephen Ingram
}

\begin{abstract}
Some philosophers object to moral error theory by arguing that there is a parity between moral and epistemic normativity. They maintain that moral and epistemic error theory stand or fall together, that epistemic error theory falls, and that moral error theory thus falls too. This paper offers a response to this objection on behalf of moral error theorists. I defend the view that moral and epistemic error theory do not stand or fall together by arguing that moral error theory can be sustained alongside epistemic expressivism. This unusual combination of theories can be underpinned by differences in the foundational norms that guide moral and epistemic inquiry. I conclude that the problem of epistemic normativity fails to show that it is compulsory for us to reject moral error theory.
\end{abstract}


Contemporary moral error theory is characterised by two claims. The first (conceptual) claim is that ordinary moral discourse is essentially committed to the existence of categorically authoritative reasons. The second (metaphysical) claim is that there are no such reasons. ${ }^{1}$ If these claims are true, then there is an error in everyday moral thought and talk.

What are categorical reasons, and why do moral error theorists deny that they exist? Firstly, a normative reason to $\Phi$ is a consideration that favours $\Phi$-ing. Sometimes these considerations are conditional on a social or psychological contingency. For instance, my reason to work late may be conditional on my desire to impress my boss. Most moral error theorists are not suspicious of these 'hypothetical' reasons, which plausibly reduce in a way that makes them metaphysically kosher. ${ }^{2}$ But moral reasons seem different. They don't seem to reduce to anything metaphysically respectable. They are irreducibly and unconditionally normative. For instance, the authority of my reason to keep a promise doesn't seem to derive from any desire or convention; it is independent of such contingencies. It is these categorical reasons that moral error theorists find intolerably 'queer.' They thus deny that any such reasons exist. $^{3}$

If categorical reasons don't exist, then there is an error in any discourse that is committed to - more precisely, that either entails or presupposes - their existence. ${ }^{4}$ If the commitment is essential to the discourse - that is, if it would be a different type of discourse without it - then the error is fatal. Error theorists about morality maintain that this is true of moral discourse. Moral discourse, they say, is essentially committed to the existence of categorical reasons. But there are no such reasons, and this means that moral discourse is fatally infected with an error.

\footnotetext{
${ }^{1}$ Mackie (1977), Garner (1990), Joyce (2001), Streumer (2013a), and Olson (2014).

${ }^{2}$ Olson (2014: 152-155) tries to reduce hypothetical reasons to the (empirically kosher) relation between desires and the means to their realisation.

${ }^{3}$ The hypothetical/categorical distinction comes from Kant, who Korsgaard (2009) and others interpret as a constructivist. Note that moral error theorists see moral discourse as involving a metaphysically 'robust' categoricity, not something constructed from agency.

${ }^{4}$ For more on how might understand commitment, see Kalf (2013).
} 
Now, according to a popular line of thought, problems arise for moral error theorists because categorical reasons feature in non-moral discourses. Specifically, some say that epistemic discourse is essentially committed to categorical reasons, that an epistemic error theory is in certain ways untenable, and that moral error theory can be rejected on that basis. ${ }^{5}$ Call this 'the problem of epistemic normativity.' I am not a moral error theorist, so my aim is not to show that this (or any other) meta-normative theory is true. I simply aim to show that the problem of epistemic normativity is one that moral error theorists can plausibly handle.

I explain the exact nature of this problem in $\S 1$, before sketching two ways of responding to it. The first response says that, even though moral discourse involves categorical reasons, epistemic discourse does not. The second accepts that epistemic discourse involves categorical reasons, but holds that an epistemic error theory is tenable. I prefer the first sort of response, and I develop a novel formulation of it (one that combines moral error theory and epistemic expressivism) throughout $\S 2$ to $\S 6$. I conclude, in $\$ 7$, that the problem of epistemic normativity does not succeed in making it compulsory for us to reject moral error theory.

\section{1}

The problem of epistemic normativity can developed in various ways, but the core idea is captured in the following argument:

(1) If moral error theory is true, there are no categorical reasons.

(2) Epistemic reasons are categorical. ${ }^{6}$

(3) So, if moral error theory is true, there are no epistemic reasons.

(4) There are epistemic reasons.

(5) So, moral error theory is not true.

This is the problem that moral error theorists must confront. ${ }^{7}$ To clarify how it works, let's consider the key premises of this argument in more depth.

\footnotetext{
${ }^{5}$ Cuneo (2007) and Rowland (2013).

${ }^{6}$ This premise can be read in different ways, depending on whether we take a robust or a deflationary view of categoricity - see n.11 for discussion.
}

${ }^{7}$ My formulation is informed by others in the literature - cf. Rowland (2013). 
(1) simply says that, if moral error theory is true, then its core metaphysical claim is too. This conditional premise is uncontroversial. (2) is controversial, however, for it concerns the nature of epistemic reasons. It says that they are categorical, or unconditionally binding. I discuss this further below, but for now we can clarify (2) by looking at the intuition that underpins it. Suppose that Control has passed secrets to the enemy. This fact is a reason to believe that Control is a traitor. The intuition underpinning (2) is that this is so whatever the social or psychological contingencies. Even if we want to believe that Control is not a traitor, that he passed secrets to the enemy is a reason to believe that he is. So, this reason is categorical. The same goes for all epistemic reasons.

Now, according to moral error theory, there are no categorical reasons. But epistemic reasons are categorical. So, if moral error theory is true, there are no epistemic reasons. This is just (3). Put another way, given the 'parity' between moral and epistemic reasons, moral error theory commits us to epistemic error theory. But epistemic error theory has intolerable implications, according to Terence Cuneo and Richard Rowland, among others. ${ }^{8}$ If this is right, then we must accept (4) - there are epistemic reasons. And, given (2), we must see these as categorical. It then follows that moral error theory is not true. That is, the existence of categorical epistemic reasons undercuts the moral error theorist's metaphysical claim; they can no longer deny that there are categorical reasons. This is how epistemic normativity is a problem for moral error theory.

In what follows I offer a response to the problem of epistemic normativity. There are two strategies that one can employ here. First, one can deny the parity between moral and epistemic reasons; that is, one can maintain that moral reasons are categorical but that epistemic reasons are not. Then moral error theory won't commit us to epistemic error theory. Second, moral error theorists might endorse the parity whilst denying that it has intolerable implications. ${ }^{9}$ Those who pursue this strategy maintain that there are no epistemic reasons, and then argue that the results are not as unacceptably bad as many critics suppose.

\footnotetext{
${ }^{8}$ Cuneo (2007: 117-122) and Rowland (2013: 13-15)

${ }^{9}$ For the first strategy, see Heathwood (2009) and Cowie (2014, 2016). For the second, see Streumer (2013a) and Olson (2014).
} 
It is clear that one cannot adopt these strategies simultaneously, for the first denies the parity and the second accepts it. My view is that moral error theorists should deny the parity. Even if the alternative is not fatal, it has costs that it would be nice to avoid. I will therefore focus on the first strategy, and in the next few sections I offer a novel version of it. I will argue that there is evidence to suggest that we can combine moral error theory and epistemic expressivism, and that the problem of epistemic normativity thus fails to decisively undermine moral error theory.

\section{2}

Those who deny the parity hold that the rejection of epistemic error theory can be sustained alongside the acceptance of moral error theory. If this is true, it must be epistemic reasons lack the categoricity of moral reasons. So, those who deny the parity must 'tame' epistemic reasons, and they must do so in a way that keeps moral error theory alive, for the risk of taming epistemic reasons is that it will lead to moral reasons being tamed too. I will provide evidence for the combination of moral error theory and epistemic expressivism. This is the view that epistemic judgements express conative states of mind. ${ }^{10}$ According to epistemic expressivism, my judgement that one ought to believe that $p$ expresses something like approval of forming that belief. It does not express a belief with normative content, certainly not one about what there is (robust) categorical reason to believe. ${ }^{11}$ Combining moral error theory and epistemic expressivism is not the only way of denying the parity, but it is a novel option that is worth outlining on behalf of moral error theorists.

\footnotetext{
${ }^{10}$ For an overview of epistemic expressivism, see Chrisman (2012).

${ }^{11}$ Complication: quasi-realists attempt to capture normative beliefs and categoricity in expressivist-friendly terms. I assume, though, that quasi-realists interpret categoricity differently to error theorists. After all, as Streumer (2013b: 451) observes, quasi-realists and error theorists either view normative beliefs and categoricity in the same way or they don't. If they do, then they agree and there is no need to write papers on it. If they don't, then their apparent agreement - on there being categorical reasons, say - masks a deeper dispute. (Roughly, whereas error theorists view it in a metaphysically robust way, quasi-realists deflate the notion of categoricity). I'm just assuming that there is a deeper dispute. What matters below is whether it's error theorists or quasi-realists who are right about moral and epistemic discourse. For more on this, see Ingram (forth).
} 
In making a case for this combination of theories, I will appeal to phenomenological evidence. I discuss the nature of such evidence below, but my use of it builds from a neat idea of Simon Blackburn's. I'll start by briefly introducing this neat idea. Imagine that you come to conclude that moral error theory is true; that is, you conclude that moral discourse is essentially committed to categorical reasons, that there are no such reasons, and that moral discourse is thus in error. Having come to this conclusion, you then decide to abandon moral discourse. That is, you stop making moral judgements and using moral language. In fact, you no longer participate in moral evaluation of any sort.

Blackburn (1993, 149-152) notes that, even in this situation, you won't stop evaluating entirely. You'll still care about what happens to the world in which you live, and you'll worry about your well-being and that of others. You'll still disapprove of terrorists, and you'll still approve of those who donate a hefty chunk of their income to charity. This may not be moral evaluation, but it is nonetheless evaluation of a practical sort. Blackburn calls it 'shmoralising.' Even after we no longer moralise, having decided that the metaphysical commitments of doing so are unacceptable, we can continue to shmoralise. But how are we to communicate our shmoral judgements? Well, why not make use of our ready-made moral vocabulary? It might be infected with an error, but we can retool it for the non-erroneous activity of shmoralising. You can say that terrorists are evil, and that they ought to be locked up. You can also say that those who give to charity are admirable, and that they act rightly.

And so on. Now comes the key move in Blackburn's argument. He thinks that, phenomenologically, moralising and shmoralising look and feel the same. He thus offers the following as a hypothesis: we were shmoralising all along. Moral discourse was never infected with an error. In making moral judgements, all we were ever doing was expressing conative attitudes like approval and disapproval. Thus, having tried to be moral error theorists, we discover the truth of moral expressivism. Moral discourse ultimately serves to express certain conative states of mind. This is neat, but I don't think it succeeds in undermining moral error theory. I explain why I think this below, but first let's consider how an analogous line of thought can be developed in the epistemic case. 
Imagine that you come to conclude that epistemic error theory is true, and you thus abandon epistemic discourse. That is, you stop making judgements about which beliefs are justified and rational, you stop telling people what they have reason to believe, and so on. Despite this, you won't stop evaluating belief entirely. You'll still care whether your beliefs are true or false, and about how you came to have those beliefs. You'll still try to avoid inconsistency in your beliefs. You'll still listen to the testimony of others, and plan to rely on it (or not) in future belief-formation. You'll still disapprove of those who change beliefs on a whim, and you'll still condemn those who dogmatically cling to false beliefs.

Thoughts of this sort can (inelegantly) be called 'shmepistemic' judgements. Even after we abolish epistemic judgement, we can carry on with shmepistemic judgement. ${ }^{12}$ And we can communicate this sort of judgement via our ready-made epistemic vocabulary. I can express my disapproval of inconsistency by saying that one ought not to be inconsistent. I can express condemnation of dogmatism by saying that it is irrational. Having planned to rely on standards for belief-formation that tend to produce true beliefs, I can say that beliefs formed this way are justified or warranted. And so on. Now we can attempt a move like Blackburn's. Phenomenologically, shmepistemic judgements look and feel like epistemic judgements, so here's a hypothesis: we were making shmepistemic judgements all along. Having tried to be epistemic error theorists we end up with a case for epistemic expressivism. That is, we find reason to think that epistemic discourse serves to express conative attitudes. ${ }^{13}$

\footnotetext{
${ }^{12}$ A referee suggests that, if Streumer (2013a) is right, this is impossible. He argues that we cannot have beliefs whilst believing that there are no reasons for belief. But what if we think that there are shmeasons for belief; considerations that we approve of being moved by in deliberation about what to believe (cf. Sinclair 2016). And what if these shmeasons for belief are reasons after all?

${ }^{13}$ Note that expressivists don't claim that descriptive facts are judgement-dependent. Moral expressivism is a metaethical view about certain normative judgements, and epistemic expressivism is a 'meta-epistemological' view about other such judgements. Chrisman nicely summarises the core idea: 'an epistemic expressivist holds that, as descriptive claims express factual beliefs, epistemic claims express a distinctive nonrepresentational kind of mental state' (2012: 119). They could argue that the descriptive facts are judgement-dependent. But epistemic expressivism, as a meta-epistemological theory, is neutral on that score.
} 
I will shortly show that the shmepistemology case for epistemic expressivism has much more going for it than Blackburn's shmorality case for moral expressivism, and that this is evidence against there being a parity between moral and epistemic reasons. The evidence that I identify is phenomenological, so we must ask how much work it can do. I argue that it does enough to show that the problem of epistemic normativity fails to make it compulsory for us to repudiate moral error theory.

\section{3}

Let's look again at shmoralising. Does it really look and feel the same as moralising, as Blackburn says? Not to me. I agree that, even if I felt forced to deny the existence of moral reasons, I would still evaluate in a broader sense. But if my evaluation could consist only in expressions of approval or disapproval, or some other conative state of mind, I am confident that I would experience a sense of loss, for I would be settling for something other and, to my mind, something less, than what was available before. More provocatively, shmorality feels to me like the 'diet' version of morality. It may be better for my metaphysical health, and I'll take it if there is nothing else on offer, but it's just not the real thing.

Now, what is this feeling of loss that I, and at least some others, would feel if we were to settle for shmorality? Note first that it is not unique to this domain. David Enoch compares it with the feelings that we would have 'if we found out (or came to believe) that Berkeley was after all right, and commonsensical objects really are just functions of impressions' $(2014,864)$. It's not as if we couldn't live in that scenario. We'd still sit on chairs, even if we saw them as 'mere' ideas in the mind. But for many of us this will mean settling for less than we'd expected. This is reflected in a feeling of loss that results from the realisation that there are no external objects or, in the case that matters here, categorical reasons. How are we to interpret this feeling of loss? To start answering this question, let's first note that the world can feel like a more or less distant place. One can feel a sense of belonging or alienation from it; reality can appear to make sense, as a place in which one can live a life of meaning. Or it can appear chaotic and disorderly, a place in which nothing means anything (cf. Ratcliffe 2008). These are the extreme ends of a spectrum, but such feelings can clarify the sense of loss I have in mind. 
Most of us want and need to experience reality as a place that makes sense, a place in which we belong. We can survive without such feelings; it isn't life-threatening in a physical sense. But they are part of a decent human life and we need them in order for our lives to feel intelligible and worthwhile. The trouble is that there are ways reality might be that could undercut one's sense of belonging within it. We thus have what I will call 'existential needs.' By this I mean that we need reality to be certain ways in order to feel that we belong within it, to experience it as an intelligible place that can support a meaningful life.

Existential needs can pertain to various aspects of reality, and different people can differ in their existential needs. For instance, we have existential needs that pertain to questions about the existence of God, but it seems likely that people differ in whether they need God to exist in order to experience themselves as belonging in the world. Some need God to exist to experience life as worthwhile, others don't. If those with the former existential needs conclude that atheism is true, they may feel a sense of despair. This is an extreme case of the relevant feeling of loss that I have in mind in comparing the shmoral and the moral.

The more general idea is that this is the feeling that we get if our existential needs go unsatisfied. Most relevant here are existential needs pertaining to choices and beliefs: we need to experience choices made for moral reasons as non-arbitrary, and the same goes for beliefs formed in light of epistemic reasons. After all, those who experience choices and beliefs as arbitrary are likely to feel a sense of alienation or loss; their actions and judgements will seem to them to lack the sort of foundation that provides a stable basis on which to conduct normative life.

The feeling of despair that an atheist might get if they come to the conclusion that atheism is true is, as I've observed, an extreme case. In many other cases the feeling of loss can be much milder; for instance, settling for less in the case of external objects won't lead most to despair, even if it is a bit disorienting. More interesting is the case of normative reasons. The question here is this: what do we need from an account of reasons to experience choices made for such reasons as non-arbitrary. In short, what does it take for a view of reasons to satisfy our existential needs? 
This is the crucial question when we examine the link between morality/shmorality and epistemology/shmepistemology. I've claimed that shmorality seems to involve settling for less. I'd feel a sense of loss with mere shmorality; shmorality is less able to satisfy my existential needs than morality. Of course, it may satisfy them to a point. It's not all or nothing; just as idealism may be less satisfying than realism but more satisfying than solipsism, shmorality may be less satisfying than morality but more satisfying than nihilism. Still, both mean settling for less. Of course, if Berkeley's idealism is true then so be it - we'll have to settle for less. And if solipsism is true then we (or, rather, I) will have to settle for much less. The same goes for Blackburn's shmorality and moral nihilism. My point is just that these views offer less than many of us expected, and this is reflected in the sense of loss that we would experience if we felt compelled to endorse these theories. We can view this feeling of loss in terms of a theory's ability to satisfy existential needs.

Now consider shmepistemology. Do shmepistemic judgements look and feel like epistemic judgements? In this instance, my feelings are less strong. In fact, I am inclined to doubt that I would experience any loss if I found that I had been making shmepistemic judgements all along. This would not feel to me like settling for less. It would not damage my sense of belonging in the epistemic world in the way that replacing morality with shmorality would with respect to the moral world; shmepistemic judgement seems much less arbitrary to me than shmoral judgement. I doubt that my normative life will be destabilised if it turns out I make shmepistemic rather than epistemic judgments. In short, the sense of loss that I associate with the idea of replacing morality with shmorality is just not replicated for the idea of replacing epistemology with shmepistemology. The experience of categoricity in epistemic life thus seems to me far less entrenched than it is in moral life.

True, this is just a description of my own moral and epistemic phenomenology. Others may feel differently, so I'll defend and explain my phenomenological claims in more depth shortly. But what's worth noting now is that, if what I've said about morality/shmorality and epistemology/shmepistemology is true, there is a phenomenological disparity between the moral and epistemic domains. This may help us to challenge the parity on which the problem of epistemic normativity relies. 
I'll make use of a thought experiment to clarify the phenomenological disparity. Imagine two planets on opposite sides of the universe. Call one 'Robustica' and the other 'Expressivia.' The inhabitants of these worlds are like Earthlings in every way; they look like us, they speak the same languages, and they live by (and argue about) the same moral and epistemic norms. The one variation is that, unlike most Earthlings, Robusticans and Expressivians have settled views on meta-normative matters.

Robusticans hold that normative language can (and often does) succeed in representing truths about robust categorical reasons. They are signed up to some form of robust normative realism. Expressivians believe that normative language is ultimately non-representational; it serves to express conative states like approval or disapproval. They are signed up to some form of expressivism. Now imagine a young fellow named Robert, strolling along on Robustica. Suddenly, whoosh! Some bright colours, some strange sounds, and some searing heat - Robert has strolled into a wormhole! The wormhole throws him all the way to Expressivia, before closing up so that he has no route back to his home world.

With no way back to Robustica, Robert must try to live among the Expressivians. What would life on Expressivia be like for Robert? If he has loved ones on Robustica, being separated from them will be devastating. Suppose, then, that he has no such ties to his home world. In fact, he is excited by the idea of adapting to a new life on Expressivia. This will help us concentrate on what Robert's normative life would be like.

Robert first encounters an ancient Expressivian culture known as the 'Emoji.' The Emoji don't bother with terms like 'right' and 'good' or 'justified' and 'warranted.' They wear a non-representational view of normative judgement on their sleeves, for they communicate such judgements simply through booing and hurrahing - rather than saying 'killing is wrong' and 'one ought to have consistent beliefs,' the Emoji just say 'boo to killing!' and 'hurrah for having consistent beliefs!' They do not seek to capture even a deflated form of categoricity in what they say. It is clear that normative life among the Emoji would be hard for Robert, for they communicate their judgements in radically different terms. 
He might understand them, but he will find it hard to engage with them on moral and epistemic matters. A debate about the ethics of euthanasia, for example, will be a non-starter because, to Robert, it will seem as if he and the Emoji are engaged in different activities. Indeed, it won't just seem to him as if the Emoji do something different. It will seem as if they do something less, for if he were to abandon normative judgement as he understands it in favour of the practice in which the Emoji engage, his existential needs would go unsatisfied. $\mathrm{He}^{\prime} \mathrm{d}$ experience a sense of loss, for Emoji normative talk doesn't seek to capture the categoricity that Robert sees as a core part of normative life.

Robert thus decides to move on from the Emoji, to see if he will have a more satisfying normative life elsewhere on Expressivia. It may be that he will, for most Expressivians are more subtle than the Emoji when communicating normative judgements. They say the same sort of things as Robert, things like 'killing is wrong' and 'one ought to have consistent beliefs.' True, their meta-normative view is that these claims serve to express conative states - maybe boos or hurrahs, but probably something like approvals, disapprovals, and plans. But this happens beneath the 'surface' of their discourse. On the surface, both Robert and Expressivians say the same sorts of thing in the same normative terms. They even share a surface commitment to categorical reasons, though Expressivians again will take a different meta-normative view about what their categorical judgements express beneath the surface. Now, to what extent will Robert fit into the Expressivians' normative life?

At first, Robert may find it easy to engage with Expressivians on normative issues. We can plausibly predict that he will initially feel no sense of normative loss, for on the surface there doesn't appear to be a difference between the way he and they participate in normative discourse. He will feel able to engage with the Expressivians on which acts are right and on what one ought to believe, for example, without it feeling as if they are participating in different practices or talking at cross-purposes. But suppose that Robert discovers the meta-normative views of the Expressivians. He discovers that, despite surface parallels in how they talk about normative matters, they have different views about what goes on beneath the surface, and on the existence of robust categorical reasons. Is this likely to disrupt Robert's moral or epistemic life? 
You may say that, if the first-order normative domain is distinct from the second-order meta-normative domain, Robert can engage the Expressivians on normative issues whatever their meta-level theories. Perhaps, but note that one can lose confidence in a first-order discourse due to second-order factors that are external it. A belief in moral error theory, for example, can lead to a loss of confidence in first-order moral discourse. So it is entirely possible that Robert's discovery will have a disruptive impact. He might see Expressivians as making shmoral and shmepistemic claims, not moral and epistemic ones, and may thus find it hard to engage with them on what he views as moral and epistemic issues. In sum, the first-order/second-order distinction fails to settle the matter.

We must therefore ask whether his awareness of Expressivian meta-normative views will disrupt Robert's normative life. Might this lead him to lose confidence in the possibility of engaging them in moral or epistemic debate? Would replacing his own practice (as he views it) with theirs lead to a sense of loss, a failure to satisfy Robert's existential needs? ${ }^{14}$

5

I predict that his awareness of Expressivian meta-normative views will have a bigger impact on Robert's moral than his epistemic life. To see why this is plausible, imagine that Robert meets some Expressivians debating euthanasia. Some of them say that it is always wrong, others that it is sometimes ok. My claim is that Robert will find it hard to see the Expressivians in this debate as moral inquirers. When he discovers that, from a second-order standpoint, they see their talk of right and wrong as giving voice to approvals and disapprovals, their debate will look to him like one that nobody can win. Even if one party moves their opponents to feel the same way about euthanasia as them, I suspect that to Robert this will look more like mob psychology than rational progress. ${ }^{15}$

\footnotetext{
${ }^{14}$ I won't claim that the expressivist nature of normative discourse must be transparent to its users. I'll just ask how we would react if it did become transparent, and I'll assess what we can learn from that reaction.

${ }^{15}$ Expressivians are more reflective than mobs, but the worry is that, to Robert, their convergence looks more like mob psychology than rational progress. The term 'mob psychology' is from Lenman (2015), an expressivist.
} 
It won't feel like that to the Expressivians, but this is no comfort to Robert, who finds it hard to take their moral debate seriously given that - at a second-order standpoint - they deny that there are robustly categorical reasons to act this way or that. ${ }^{16}$ Even if they converge on a view about euthanasia, Robert will experience a troubling arbitrariness about this process. This is why I say that, to Robert, an Expressivian's success in converting opponents is like mob psychology; the way their views are caused to change seems to him too arbitrary to constitute progress.

I'll say more on this shortly, but first let's ask whether we can predict something similar about Robert's epistemic life among the Expressivians. I don't think that we can. I suspect that discovering their meta-normative views will not disrupt his ability to engage them on questions about what one ought to believe, and so on. To see why this is plausible, imagine that Robert meets some Expressivians debating whether they should believe that Control is a traitor. Some say they should believe this, because he passed secrets to the enemy. Others say that they shouldn't, claiming that there must be another explanation given that Control has always been so effective in preventing enemy attacks.

The question that matters here is this: how seriously can Robert take this Expressivian debate once he discovers that - at a second-order standpoint - they understand their talk of what one should believe in fundamentally non-representational terms. Pretty seriously, I think, for there is a clear way in which the debate can be won that will seem non-arbitrary even to Robert. This is down to the intimate connection between belief and truth. Or, more accurately, the connection between forming beliefs and seeking the truth. It's commonly said that belief 'aims' at the truth, though this image is notoriously hard to unpack. ${ }^{17}$ However we view the details, there is clearly an intimate relationship between deliberation about whether to believe that $p$ and deliberation about whether $p$ is true. Similarly, debate about whether one ought to believe that $p$ is intimately related to debate about whether or not $p$ is true.

\footnotetext{
${ }^{16}$ Expressivians reject a robust metaphysical view of categoricity, but accept a deflated view of it. Hence the surface similarity between their discourse and Robert's.

${ }^{17}$ Cf. Wedgwood (2002).
} 
I won't assume that this intimacy rises to a conceptual link. I'll just assume that its level of intimacy reflects the fact that, if inquiry into what one ought to believe does not map onto inquiry into what is true, the ability of epistemic communities to converge on judgements about what one ought to believe will be undercut. That is, whatever we say about the exact nature of the truth/belief relationship, it is close enough to sustain the shared hope that, given sufficient time and resources, conscientious inquirers will converge in their judgements about what they ought to believe. This matters, for it is a regulative ideal of inquiry that, again with time and resources, we can converge on the truth. We may sometimes fail to reach this ideal, but it is still a core aspiration of inquiry.

For instance, scientists doing cutting-edge research disagree on various questions, but even as they argue their inquiry is guided (more or less implicitly) by the idea that they will ultimately converge on the right answers. This aspiration (of converging on the correct answers to controversial questions) is also part of normative inquiry. This is not to claim that debate won't bottom out in fundamental disagreements on at least some questions of what we ought to do and believe. It's just to claim that, when we argue about these questions, our inquiry is guided by the hope that we will converge on the right answers to them. So, if we do find ourselves in a fundamental disagreement on a question of what we should do or believe, or indeed any matter of controversy in which determinate answers are possible, this is troubling. It feels like failure.

My claim is that, to sustain this ideal of converging on the right answers to controversial questions, we must assume that inquiry into what one ought to believe maps on to inquiry into what is true. We can see this by imagining a potential rival to the truth norm. Suppose that inquiry into what one ought to believe is tied to inquiry into what it would be useful to believe. Such a view makes convergence less likely, as the usefulness of a belief will be indexed to practical ends, and there are fundamental differences in such ends. If a usefulness norm guides inquiry into what one ought to believe, and if there are fundamental differences in our practical ends such that it would be useful for me to believe that $p$ (this helps me $\Phi$ ) but useful for you to believe that not- $p$ (this helps you prevent my $\Phi$-ing), then we'll arrive at incompatible views on what we ought to believe, and the ideal of converging will be undercut. 
The usefulness norm thus undercuts the ideal of convergence in this inquiry. ${ }^{18}$ To sustain this ideal, we thus need to be guided by a norm that is not indexed to ends (or whatever) about which we differ fundamentally. Truth is not relative to our practical ends, and is thus a strong candidate for the norm that sustains the regulative ideal of converging on the right answers to controversial questions. We can thus hold that Expressivian inquiry into what one ought to believe is guided by the truth norm. It must be, for otherwise their inquiry can't aspire to the ideal of converging on the correct answers to controversial issues, such as whether Control is a traitor. And we can be sure that Expressivians will have this aspiration. This is because we have it, and they are just like us except in their having considered meta-normative views.

That it is guided by the truth norm means that the Expressivian debate has a standard for success and failure, for winning and losing. The winners in debate over what one ought to believe about Control are those who get at the truth, the losers are those who don't. And, if what I've said above is correct, this truth norm will be widely shared by the participants in this debate. This is because, in general, when we participate in inquiry, we aspire not only to discover the truth for ourselves, but also to converge on it with other participants in the inquiry.

So, the Expressivian debate about Control will be guided by the truth norm. And this is a norm that will feel non-arbitrary to Robert. Since the aim of the debate is to discover what one should believe, and since deliberation about what one should believe is tied to deliberation about what is true, the truth norm gives a standard for success that will seem well-founded to Robert. It provides a stable foundation to a core ideal of epistemic inquiry as he sees it; converging on the right answers to our questions. So, if one side convinces the other that they should judge Control a traitor, this will not feel like mob psychology to Robert. There's a non-arbitrary norm (the truth norm) that guides Expressivian efforts to revise and refine the conative states their fellows express in inquiry.

\footnotetext{
${ }^{18}$ A referee notes that, since it is often useful to believe the truth, a discourse following the usefulness norm might be indistinguishable from one following the truth norm. But as long as it is sometimes useful to have a false belief, the discourses considered as a whole will be distinguishable.
} 
Of course, if the Expressivians are right in their meta-normative views then their acceptance of the truth norm - that is, their view that it is the correct substantive norm for substantive epistemic debate - is itself an expression of a conative state. It is not seen as having any sort of metaphysically robust authority. If a rebel Expressivian decided to reject the truth norm, other Expressivians might therefore seem to lack the meta-normative resources to say that the rebel makes a normative mistake. And one might think that this would be troubling to Robert's epistemic life, maybe troubling enough to make it difficult for him to engage with the Expressivians on questions about what one ought to believe. After all, an attraction of the robust view of categorical reasons is that it gives the resources to accuse the rebel of making a normative error.

However, there is something that Expressivians can say to the rebel. They can say that, if he fails to be guided by the truth norm, he will (as a result) jeopardise his ability to be guided by the ideal of our converging (given enough time, etc.) on the truth. This ideal is one to which he is highly likely to aspire, at least if (psychologically speaking) he is anything like other Expressivian inquirers. So the Expressivians can say that the rebel goes wrong in his own terms if he rejects the truth norm. ${ }^{19}$

Note as well that the aspiration of converging on right answers to controversial questions is not something that Robert will experience as arbitrary, for it's likely to be something about which he cares. We can know this because we are the sort of creature who tends to care about this sort of thing, and (by stipulation) Robert is like us, except in his having come to considered meta-normative views. He won't even be worried by the idea that there is no categorical reason to be guided by the ideal of converging on the truth, for he need never have thought that there was such a reason. Aspiring to convergence on the truth is one thing, thinking that one has categorical normative reason to have this aspiration is another. The mere aspiration is enough to support the truth norm, which in turn provides Expressivian inquiry into what one ought to believe with what seems to Robert to be a stable, non-arbitrary foundation.

\footnotetext{
${ }^{19}$ They might also say, with quasi-realists, that the claim that the rebel has categorical reason to obey the truth norm is itself a normative claim that expressivists can capture in their own terms.
} 
This clarifies the proposed difference in how Robert reacted to his discovery of the Expressivians' meta-normative views, for there is not (or at least does not appear to be) anything similar going on in the moral case. There is nothing as intimately connected to action as truth is connected to belief. In other words, there is no moral norm that has such an intimate connection with the very idea of engaging in moral inquiry, and that could thus non-arbitrarily guide that inquiry. ${ }^{20}$ Thus, whilst Robert is likely to see Expressivians as engaged in the same sort of epistemic practice as him, he is unlikely to see them as engaged in the same sort of moral practice. Coming to see things in this way might lead Robert to ask whether his use of epistemic discourse really ever did involve categorical reasons, even if he will likely remain sure that his participation in moral discourse has indeed always involved such reasons.

Plausibly, then, Robert will see the Expressivians as engaged in shmoral rather than moral judgement, but it is less plausible to predict that he will see them as engaged in shmepistemic rather than epistemic discourse. What the Expressivians see as their moral practice is not able to satisfy Robert's existential needs; he would feel a sense of loss if that were all there is to debate about what one ought to do, for it wouldn't rest on anything that seems non-arbitrary to him. This isn't so in debate about what one ought to believe, which is grounded by a non-arbitrary norm.

\footnotetext{
${ }^{20}$ What about the Kantian views of Korsgaard (2009) and others, on which there are norms that derive from the very nature of rational agency? The norms in question are formulations of the Categorical Imperative, which can then guide moral inquiry just as the truth norm guides epistemic inquiry. This would be an appropriate analogue to the truth/belief case. The trouble with appealing to this idea, however, is that it is itself a very controversial ethical view (cf. Hussain and Shah 2006). So, to defend this moral view on would have to engage in moral inquiry. And what non-arbitrary moral norms can guide this inquiry without begging the question against rival moral views? But maybe we don't need as controversial a moral view as this to get an analogue. A referee notes that reasons may be as closely related to action as truth is to belief, in that to act deliberately is to (tacitly) believe oneself to act for a reason, or in line with some set of reasons. This may be true, but this sort of link doesn't give a thick enough norm for genuinely non-arbitrary guidance in moral inquiry. This is because it doesn't tell us how to assess which facts count as reasons to act this way or that. Whereas the truth norm gives a non-arbitrary standard by which to assess inquiry into what one ought to believe, the proposed link between reasons and action doesn't - it's just too thin for that.
} 
A potential reply to this line of thought is that, if Expressivians live by and argue about the same sort of moral norms as we Earthlings do, then they will share a bunch of moral norms that could potentially form a stable foundation for their inquiry. For instance, they will agree on norms like 'do good' and 'trial by combat is a rubbish way to settle matters of justice.' One thing to note about these norms is that they are of little use in guiding inquiry; the former is too general and the latter too specific to help with hard cases like euthanasia. ${ }^{21}$ But we shouldn't place too much significance on this point, for the same may apply to the epistemic case. The presence of a non-arbitrary truth norm doesn't mean that Expressivian deliberation on what one should believe will be simple, or that they will always arrive at the appropriate view on this.

After all, we know from life on Earth that this is not the case, and we philosophers know from the history of epistemology that it is hard to derive various specific epistemic norms from the more general link between truth and belief. ${ }^{22}$ I don't deny this, but it's not what matters here. What matters is whether Robert - a Robustican - sees the first-order epistemic debate (about Control, about specific epistemic norms, etc.) of Expressivians as grounded in a non-arbitrary standard of success. I think he can. Even if it is hard to achieve success in specific cases, the effort to do so is grounded by a norm that he does not see as arbitrary.

\footnotetext{
${ }^{21}$ If someone asked you for advice on whether they should help their elderly parent to die, you wouldn't be much help if you said 'do good' or 'do the right thing.' After all, you can say this in any situation; it doesn't give any euthanasia-specific advice; it's too general to guide moral inquiry in hard cases. Similarly, saying 'avoid trial by combat' is only useful moral advice in a very specific set of situations - those in which this was something your advisee was considering. It won't guide inquiry in the hard cases, like euthanasia.

${ }^{22}$ Whilst the truth norm non-arbitrarily governs epistemic success, and should thus constrain epistemic policy-making, there are controversies over which specific policies generate the relevant sort of success. These won't be straightforwardly settled by our just staring at the truth norm. Even if we mostly agree on a policy of using a certain form of reasoning - inference to the best explanation, say - there is controversy about why this is so, and on how to weigh it against other forms of reasoning. And there may be other specific policies - the method of reflective equilibrium, say - that are more controversial in themselves. I am grateful to Mark Schroeder and Daniel Whiting for pressing this point.
} 
This is the truth norm, and he experiences it as non-arbitrary because of its intimate tie to belief, which is the pivotal element in the relevant debates. The idea is that moral debate among Expressivians has no analogue to the non-arbitrary ground that the truth norm gives in the epistemic case. Here's another way to put the point. Robert and the Expressivians both see judgements about what one should believe as being guided by how the world is. Given their adherence to the truth norm, along with obvious facts about the nature of truth, both are guided by something like the following thought: if $p$ is true, then you ought to believe that $p$, and $p$ is true iff $p .{ }^{23}$ So what you ought to believe is seen, by both Robert and the Expressivians, as linked to how things are.

There doesn't seem to be any clear equivalent in the moral case. Even if we view, say, 'do good' as the counterpart to 'believe the truth,' we don't get far. This would lead us to something like this: if $a$ is good, then (other things being equal) you ought to do $a$, and $a$ is good iff [????]. For the Expressivian, it's not at all clear how to fill the blank in a way that Robert would experience as stable and non-arbitrary. As a Robustican, of course, Robert can fill in the [????] in a way that will seem non-arbitrary to him. He can say that $a$ is good iff there is a robust moral fact (or norm, or property, or whatever) according to which $a$ is good.

But the Expressivian cannot say this, and given that there's no widely accepted 'goodness schema' to play the role played by the truth schema (' $p$ is true iff $p^{\prime}$ ) in the epistemic case, from Robert's position the Expressivian debate about euthanasia will look arbitrary in a way that their debate about Control won't. This is why I predict a difference in how Robert will fit into moral and epistemic life on Expressivia. In short, for Robert, there is a phenomenological disparity between the moral and the epistemic domains, and this is revealed to him on Expressivia.

\footnotetext{
${ }^{23}$ Two things to note. First, strictly speaking, this principle should be reformulated to avoid implying that we ought to believe every true proposition. After all, so many of them are trivial, and we don't have an obligation to believe these trivial truths. I set this wrinkle aside, however, for brevity. Second, in using the ' $p$ is true iff $p$ ' schema I assume nothing contentious about the nature of truth. This schema will be accepted by deflationists and correspondence theorists alike, they just build on it in different ways.
} 
6

The discussion in $\S 5$ was an idealisation. Unlike the Robusticans, most Earthlings have not thought hard about meta-normative matters. Still, we can consider whether my predictions about Robert's normative life on Expressivia also apply to Earthlings in a similar situation. I predict that, just as Robert is led to experience a disparity between moral and epistemic discourse, many Earthlings will also be led to experience this disparity. The experience of these Earthlings might be less stark, but it will nevertheless lead them to see the discourses as involving different commitments.

This moves us in the direction of a response to the problem of epistemic normativity. We can deny the parity on which this problem depends, for there is phenomenological evidence against it. What the considerations outlined above indicate is that many of us experience moral normativity as robustly categorical, but that the same is not true of epistemic normativity. To clarify, let's return to the shmoral and the shmepistemic. We have seen that careful examination casts doubt on Blackburn's claim that moralising and shmoralising look and feel the same - at least to those of us who are like Robert. But close examination supports the hypothesis that epistemic and shmepistemic judgements look and feel the same - at least to those of us who are like Robert. The shmorality case for moral expressivism is thus unconvincing, but the shmepistemology case for epistemic expressivism has more going for it. And this is evidence for a difference in the discourses. It is a reason to repudiate the parity on which the problem of epistemic normativity relies.

But the matter is a little more complex, for Earthlings may differ in their existential needs. Perhaps some of us need robustly categorical facts about reasons in order to experience moral choices and inquiries as non-arbitrary. Others, however, plausibly need to deny that there is any independent categorical authority. Maybe they find it liberating or life-affirming to think that they can forge their own paths; that the only restrictions they face are those that they themselves endorse. These differences in existential need mean that different Earthlings might have different experiences if transported to Expressivia. Some will have the same sort of experience as Robert the Robustican, being led to a phenomenological disparity, whilst others may have a very different experience. 
This raises an important question: how much significance does phenomenological evidence for a normative disparity merit, given that phenomenologies may differ? Clearly, phenomenological evidence is defeasible. It comes from how things appear, and appearances don't always match reality. This means that my reply to the problem of epistemic normativity will be defeasible; even if we all experienced the relevant normative discourses as having different commitments, we'd have to allow that argument might make us see these as illusory. That's fine, but in actual fact we don't all experience the discourses as having different commitments. So, what is the significance of the fact that some of us experience both of them as committed to robust facts about reasons?

This affects the nature of the response, but does not undermine it. Consider the dialectic. The moral error theorist maintains that moral discourse involves an error; it is essentially committed to non-existent categorical reasons. The critic offers a reply that relies on the intuition that there are categorical reasons in epistemic discourse. For this reply to make the rejection of moral error theory compulsory, we must share that intuition. But many of us don't experience epistemic discourse as involving categoricity, even though we experience moral discourse as robustly categorical. ${ }^{24}$ And this places critics in an awkward dialectical position. For now their objection relies on intuitions that many of us lack. ${ }^{25}$

\footnotetext{
${ }^{24}$ A referee asks why, if this is so, the companions in guilt argument is so popular, and why the reply I offer has not been developed before? On the first question, my answer is that whilst many of us lack the phenomenology required to make the problem of epistemic normativity have some dialectical bite, others may differ in phenomenology. People can differ in existential need, and can thus differ in what they experience as arbitrary. The key thing, as I say below, is that the problem of epistemic normativity puts no rational pressure on those without the phenomenology required to support it. On the second question, I'd suggest that phenomenology need not be transparent, and it can take work to elucidate it - I hope to have done some of this work in relation to the phenomenology of normative discourse above. So it need not be a surprise that the reply offered here has not been offered before.

${ }^{25}$ Defenders of the problem of epistemic normativity might respond by suggesting that there is more to the defence of robust reasons than intuition and phenomenology. A referee suggests that they may instead make a claim about what best explains our practice. If what I've said above is correct, however, the phenomenological evidence counts against thinking that a robust view of reasons best explains epistemic practice.
} 
They therefore fail to make the rejection of moral error theory compulsory. This does not mean that moral error theory is true. But it does mean that the problem of epistemic normativity fails to make it compulsory for us to see it as false. ${ }^{26}$ More generally, if a philosophical argument for or against some given theory relies on certain intuitive or phenomenological considerations, it will only put rational pressure on (and, ideally, render its conclusion compulsory for) those who share the relevant intuition or phenomenology. Those who differ in intuition or phenomenology will be not be put under any rational pressure to accept the conclusion. I suggest that this sort of consideration helps the moral error theorist to deal with the problem of epistemic normativity. If they have the sort of intuitions and phenomenology sketched above, then they are not under any rational pressure to repudiate moral error theory.

\section{7}

Moral error theorists can handle the problem of epistemic normativity by defending epistemic expressivism. This is not to suggest that either theory is in fact true. The phenomenological evidence may ultimately be overturned by further argument. But there is some support for this combination of theories, and it is enough to ensure that the problem of epistemic normativity fails to make it compulsory for us to repudiate moral error theory. So, the moral error theorist has reason to develop and defend an expressivist theory of epistemic discourse. When confronted by the problem of epistemic normativity there is thus a new and promising way for moral error theorists to respond. They can say epistemology shmepistemology.

\footnotetext{
${ }^{26}$ Could we perhaps say something stronger, perhaps to the effect that the objection simply fails full stop, rather than that it fails merely to make it compulsory for us to reject moral error theory? I'm reluctant to say this on the basis of phenomenological evidence, for (as I've already suggested) the normative phenomenology of Earthlings is less clear than that of a Robustican like Robert. He is an idealisation, a useful case against which we can compare Earthlings. But the idea that we're all like him in our normative phenomenologies is a stronger empirical conjecture than I'm prepared to make at this point. I am prepare to suggest that many Earthlings would have a similar experience to Robert if marooned on Expressivia, but I'm not prepared to say this of everyone.
} 


\section{Acknowledgements}

For helpful comments and discussion, I'm grateful to Jimmy Lenman, Miranda Fricker, Graham Bex-Priestley, Lewis Brooks, Steve Wright, Phil Rau, Lizzy Kirkham, Denise Fox, Shirley Carter, and two referees for this journal. I am also grateful to two audiences at the University of Sheffield and participants in the Normativity: Epistemic and Practical event at the University of Southampton - questions from Kurt Sylvan, Daniel Whiting, Elizabeth Harman, Jonathan Way, and Mark Schroeder, were particularly helpful in improving this paper.

\section{References}

Blackburn, S. 1993. "Errors and the Phenomenology of Value." In Essays in Quasi-Realism. Oxford: Oxford University Press: 149165.

Chrisman, M. 2012. "Epistemic Expressivism." Philosophy Compass 7: 118-126.

Cowie, C. 2014. "Why Companions in Guilt Arguments Won't Work." The Philosophical Quarterly 64: 407-422.

Cowie, C. 2016. "Good News for Moral Error Theorists: A Master Argument Against Companions in Guilt Strategies." Australasian Journal of Philosophy 94: 115-130.

Cuneo, T. 2007. The Normative Web: An Argument for Moral Realism. Oxford: Oxford University Press.

Enoch, D. 2014. "In defence of Taking Morality Seriously: reply to Manne, Sobel, Lenman, and Joyce." Philosophical Studies 168: 853-865.

Garner, R. 1990. “On the Genuine Queerness of Moral Properties and Facts." Australasian Journal of Philosophy 68: 137-146.

Heathwood, C. 2009. "Moral and Epistemic Open Question Arguments." Philosophical Books 50: 83-98.

Hussain, N.J.Z. and N. Shah. 2006. "Misunderstanding Metaethics: Korsgaard's Rejection of Realism." In Oxford Studies in Metaethics 1, edited by R. Shafer-Landau, 265-294. Oxford: Oxford University Press. 
Ingram, S. Forth. “I Can't Relax! You're Driving Me Quasi!” Pacific Philosophical Quarterly.

Joyce, R. 2001. The Myth of Morality. Cambridge: Cambridge University Press.

Kalf, W.F. 2013. "Moral Error Theory, Entailment, and Presupposition." Ethical Theory and Moral Practice 16: 923-937.

Korsgaard, C.M. 2009. Self-Constitution: Agency, Identity, and Integrity. Oxford: Oxford University Press.

Lenman, J. 2015. “Moral Inquiry and Mob Psychology." In The Palgrave Handbook of Philosophical Methods edited by C. Daly, 637-651. Basingstoke: Palgrave MacMillan.

Mackie, J.L. 1977. Ethics: Inventing Right and Wrong. London: Penguin.

Olson, J. 2014. Moral Error Theory: History, Critique, Defence. Oxford: Oxford University Press.

Ratcliffe, M. 2008. Feelings of Being: Phenomenology, Psychiatry, and the Sense of Reality. Oxford: Oxford University Press.

Rowland, R. 2013. "Moral Error Theory and the Argument from Epistemic Reasons." Journal of Ethics and Social Philosophy 7: 124.

Sinclair, N. 2016. "Reasons, Inescapability and Persuasion." Philosophical Studies 173: 2823-2844.

Streumer, B. 2008. 2013a. "Can we Believe the Error Theory?" Journal of Philosophy 110: 194-212.

Streumer, B. 2013b. “Do Normative Judgements Aim to Represent the World?" Ratio 26: 450-470.

Wedgwood, R. 2002. “The Aim of Belief." Philosophical Perspectives 16: 267-297. 